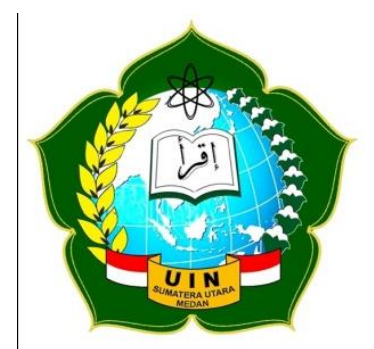

VISION JOURNAL

http://jurnaltarbiyah.uinsu.ac.id/vision

\title{
AN ANALYSIS OF PROFANITY UTTERED BY MALE AND FEMALE INDONESIAN YOUTUBERS \\ Windy Ariani ${ }^{1}$, Farida Repelitawaty Br. Kembaren ${ }^{2}$ \\ Email: windyariani70@yahoo.com, titaancha@gmail.com \\ Department of English Education, State Islamic University of North Sumatera
}

\begin{tabular}{|c|c|}
\hline Keywords & Abstract \\
\hline $\begin{array}{l}\text { Keywords: Profanity, Male and } \\
\text { Female, Youtube. }\end{array}$ & $\begin{array}{l}\text { This research aimed at discovering: (1) the types of profanity } \\
\text { uttered by male and female Indonesian Youtubers; (2) the } \\
\text { reasons for male and female Indonesian Youtubers in uttering } \\
\text { profanity in their videos. This research used qualitative method } \\
\text { as the research design. The subjects of this research were male } \\
\text { and female Indonesian Youtubers whose videos were analyzed } \\
\text { to find out the types of profanity and the reasons for using those } \\
\text { profanity. The data collection was done by using observation } \\
\text { technique and audio-visual digital materials. The data were } \\
\text { analyzed by using interactive model proposed by Miles and } \\
\text { Huberman which consisted of three steps namely data } \\
\text { reduction, data display and conclusion drawing/verification. } \\
\text { The findings of this research showed that: (1) there were four } \\
\text { types of profanity uttered by male and female Indonesian } \\
\text { Youtubers in their videos. The types were expletive, abusive, } \\
\text { humorous, and auxiliary profanity, and; (2) there were five } \\
\text { reasons for male and female Indonesian Youtubers in using } \\
\text { profanity. The reasons were to draw attention, to offend, to } \\
\text { convey negative thought, to respond pain or misfortune and to } \\
\text { make fun or jokes. }\end{array}$ \\
\hline
\end{tabular}

Faculty of Tarbiyah and Teacher Training, 1st Floor

Jalan Willem Iskandar Psr V Medan, 20731

Telp. 061- 6622925 - Fax. 061 - 6615685

\section{INTRODUCTION}

Men and women can be distinguished from the use of adjectives, the use of verbs, and the use of pronoun (Trudgill, 2000). In written form of language found in Facebook status updates, females publically tended to like more Facebook status updates than males and 
females tended to post more emotionally than males (Joiner et al., 2014). In private messages, there are no significant differences between male and female in using language. Even though, females are more likely to send a private messages than males, however the difference is very small.

The other study which conducted at STAIN Kudus showed that men and women are different in using language (Wahyuningsih, 2018). The differences are in using vocabulary (adjectives, color words, adverbs, pronouns, diminutives, expletive and swear statements), attitude, syntax (modulation, interrogative sentences, imperative sentences, grammar correct) and non-verbal expressions. The interesting result of this study is that the difference between men and women in using swear words. A conversation held in public place which is categorized as religious environment such as STAIN Kudus, men and women avoiding the use of swear words since these words are considered to be taboo words and it can create uncomfortable communication. However, this case seems to be contradictory in other public communication such as in Youtube videos.

Nowadays, Youtube is one of the popular social media platform in many countries including Indonesia. Youtube is a platform with over 1,9 billion logged-in users per month which enables users to share videos (Moloney \& Sylva, 2020). Youtube is also called as the new television. Youtuber is a term which refers to the creator of Youtube content. Profanity or well-known as swear words frequently found in Youtube (Wulandari, 2017). Some Youtubers used swear words in their videos as the way to convey their ideas or to express their feelings. This profanity sometimes became the characteristics of the Youtubers so that the viewers attracted to watch their contents. Though, there are many viewers who avoid such videos. Profanity is a term which refers to swearing, bad language, indecent speech, foul language, vulgar language, verbal obscenity, swear words, coprophasia, obscene wit, obscene humor, and dirty jokes. The word profanity comes from Latin fanum which means "a temple," and when the words are taken into Middle English they carry this etymological sense of "to desectrate or violate a temple," before being applied to more secular objects (Of, 2006). Profanity or swear words were classified into four categories namely expletive swear words, abusive swear words, humorous swear words and auxiliary swear words (Trudgill, 2000). Expletive swear word is profanity language which show emotion, expression and feeling such as anger, happiness, frustration, sadness and excitement. Abusive swear word is the opposite of expletive swear word, it is meant to insult, offend or abuse other people. Humorous swear word is a swear word 
to make fun or to create joke with other. And auxiliary swear word is meant to emphasize and strengthen other words.

In recent times, the use of profanity (swear word) has been spread widely. There are many negative opinions regarding the profanity but there is little actually known about the harm of it (Feldman et al., 2017). Profanity delivers a message whilst sending out emotion. This emotion is intended to grab attention of people in communication.

Profanity is not only used by adult people but also used by children. A study showed that elementary students often used profanity words (Suganob-Nicolau, 2016). The use of profanity is related to intellectual based terms and religion, anger, offensive tone and it is revealed that their mothers are the most contributive figures for the children to learn how to use the profanity words. Furthermore, movie is also considered to be one of the sources for people learn how to swear.

Profanity is uttered by the language users in Youtube channels to attract the attention of the viewers to watch the video. One of the most popular male Indonesian Youtubers is $D C$ whose Youtube channel known as one of the most popular Youtube Podcast. This Youtube channel, which has approximately 13.5 million subscribers, is one of the most popular channel in Indonesia. There many viewers from different ages, backgrounds, genders, and social status who watch the videos. Based on the preliminary observation, it is found that there are some profanity words uttered by this popular Youtubers.

Another example of profanity used by female Indonesian Youtuber can be seen in $K H$ Channel. This Youtube channel is owned by a famous female gamer. Her Youtube contents broadcasted game play of many popular mobile games. $K H$ created her first Youtube videos in 2016 and less than 5 years, her channel is subscribed by more than 2 million of viewers. Most of her viewers are children who played the similar game she broadcasted in her channel. The fact that $\mathrm{KH}$ uttered some of profanity words in her channel become a serious issue since her channel is watched by children.

There are many other expressions or words in the videos of male and female Indonesian Youtubers which categorized as profanity. The further investigation is required to be conducted in order to provide sufficient information on the types of profanity, why they are used, and the differences between male and female in using profanity in their Youtube videos. In social life, there is a belief that profanity is used by people with less integrity. High integrity person would avoid using bad language especially in public. But, there is an interesting result of a study which explained that there is a positive relationship between profanity and integrity (Feldman 
et al., 2017). The study showed that people (participants in the study) with higher profanity were more honest in expressing their unfiltered feelings (such as anger, frustration, surprise and etc) than those who don't.

Even though there are many researchers who study profanity viewed from gender perspective, there is only a few which study the use of profanity on Youtube contents. Therefore, the analysis of profanity uttered by male and female Indonesian Youtubers is needed to be conducted. This research is expected to provide new insight about the use of taboo words in public communication. This research is also expected to enrich the knowledge about the use of language in social life.

\section{LITERATURE REVIEW}

\section{Profanity language}

Language has an important role in life. It is used in almost every aspects of live. In order to maintain a good social life, the societies are required to be able to use proper language and proper manner in conveying their thoughts, expressions and messages to other people.

The word profanity comes from Latin fanum, which means "a temple," the word then carries an etymological sense of desecrating or violating a temple (Of, 2006). Profanity refers to obscene, lewd, abusive, swearing, and bad language. Profanity or often called as bad language consists of swearing, oaths, and curses (Byrne, 2016). Profanity is also well-know with the term of swearing. Mohr states that the first swearing begins two thousand years ago in Rome (Shit, 2014). The concept of profanity is guided by the Roman idea of obscenitas (obscene words) along with republicanism, the Julian calendar, and numerous literary classics.

Profanity referred to obscene language such as taboo and swear words which are considered inappropriate in social contexts and unacceptable in some situations (Feldman et al., 2017). Profanity is often related to sexual references, blasphemy, objects eliciting disgust, ethnic-racial-gender slurs, vulgar terms, or offensive slang. The use of profanity in society is widely spread. It is uttered by people from various age, gender, background and social status. The use of profanity sometimes leads to social conflict because the word is considered to be offensive and abusive. Therefore it is important to see the context where and when the profanity is uttered.

Based on the explanation given by some experts above, it can be stated that profanity is bad language or mostly known as swear words, taboo words, inappropriate language which 
sometimes leads to the violation of norms and morality and it can end in social conflict between the language users. Therefore, in order to have better understanding of the profanity, it is necessary to look out for the context so that the conflict or the violation can be avoided.

Profanity or swear words were classified into four categories (Trudgill, 2000). They are: (1) Expletive swear words: swearing that show emotion, expression and feeling such as anger, happiness, frustration, sadness and excitement; (2) Abusive swear words: swearing that meant to insult, offend, or abuse other people. It is the opposite of expletive swear words; (3) Humorous swear words: swearing that create fun or joke with other people, and; (4) Auxiliary swear words: swearing that emphasize or strengthen other words.

From Trudgill's category of profanity, it can be seen that swearing is used in almost every situation. It can be used to show happiness, anger, frustration, sadness and excitement. Profanity can be used to create fun between the speaker and the listener, to emphasize certain words so that the meaning can be received by the receiver well. However, profanity can also be used to offend people. This type of profanity should be avoided because it can create conflict between the speaker and the listener. It will be better if people can be a successful user of profanity. Successful user of profanity means that the people who swears does not seem to offend their listener (Mercury, 1995).

The reasons for using profanity depended on the person and the situation (Feldman et al., 2017). People commonly use it to express emotions such anger, frustration, or surprise. It is also used to express a disappointment or an incompetence towards oneself (Suganob-Nicolau, 2016). The reasons for using profanity are important to be investigated since they can provide information whether the utterances are acceptable or not. In order to investigate the reasons why people use profanity, the analysis should be related to the classification of profanity as has been explained in the previous section.

There are five reasons for using profanity (Pinker, 2008). They are: (1) Intended to offend, intimidate or otherwise to cause emotional or psychological injuries; (2) To respond pain or misfortune; (3) To convey that the speakers thinks negatively of the subject matter and to make the listener do the same. (4) To draw attention, and; (5) To sign that the speaker and the listener are in informal conversation.

The reasons for using profanity are determined by the person who uses it and the situation where and when the profanity is used. Profanity can be interpreted as abusive, antisocial, or harmful if it is used to offend, intimidate or to cause emotional or psychological harm. It can be interpreted as a response to the particular situation. It also can be used to affect people, 
drawing attention and to create a sign that the relationship between the speaker and the listener is informal or in a close relationship.

Therefore, it is important to pay attention to the context when the profanity is used by people. So that the better understanding about the reasons for using profanity can be obtained and the misunderstanding can be avoided. The explanations about the reasons for using profanity enable the researcher to decide the motives of profanity uttered by male and female Indonesian Youtubers in their videos.

\section{METHOD}

This research used qualitative method as the research design. Qualitative method was an approach in research which rely on text and image data, have unique steps in data analysis, and draw on diverse (Creswell \& Creswell, 2018). This research investigated the types of profanity and the reasons of male and female Indonesian Youtubers using profanity in their videos. The profanity uttered by male and female Indonesian Youtubers were captured by observing or watching their videos and the lists of profanity used by male and female Indonesian Youtubers were made.

The subject of this research was male and female Indonesian Youtubers whose videos were analyzed to find out the types of profanity and the reasons for using profanity in their Youtube videos. There were five male and five female Indonesian Youtubers selected as the subject in this research. The criteria of selection were as follow:

1. Top five largest subscribers for male and female Indonesian Youtubers.

2. The profanity was uttered in Indonesian language and/or English.

3. Having the variation of Youtube videos.

4. Uploading videos regularly in Youtube.

Based on Youtube channel rank (https://id.noxinfluencer.com/Youtube-channelrank/top-100-id-all-Youtuber-sorted-by-subs-weekly) which was accessed on Saturday, March 62021 , it can be seen that there a hundred Youtube channels listed on the site. In order to meet the need of the study, the researcher listed the top five male and five female Indonesian Youtubers.

In collecting the data, this research used two kinds of data collection, namely observation and audio-visual digital materials (Creswell \& Creswell, 2018). The data were analyzed using interactive model which consisted of three steps (Miles \& Huberman, 1994). They were: (1) Data Reduction; (2) Data Display; (3) Conclusion Drawing/Verification. 


\section{FINDING AND DISCUSSION}

After analyzing the data, there were several important to be discussed in this research. Male and female Indonesian Youtubers used profanity in their Youtube videos. There were four types of profanity (Trudgill, 2000). They were expletive, abusive humorous and auxiliary profanity. These four types of profanity were used by male and female Youtubers in their videos. Male and female were different in using language (Tanen, 1991). In using profanity, male and female were also different. Male Youtubers used expletive profanity 27 times, while female used 41 expletive profanity.

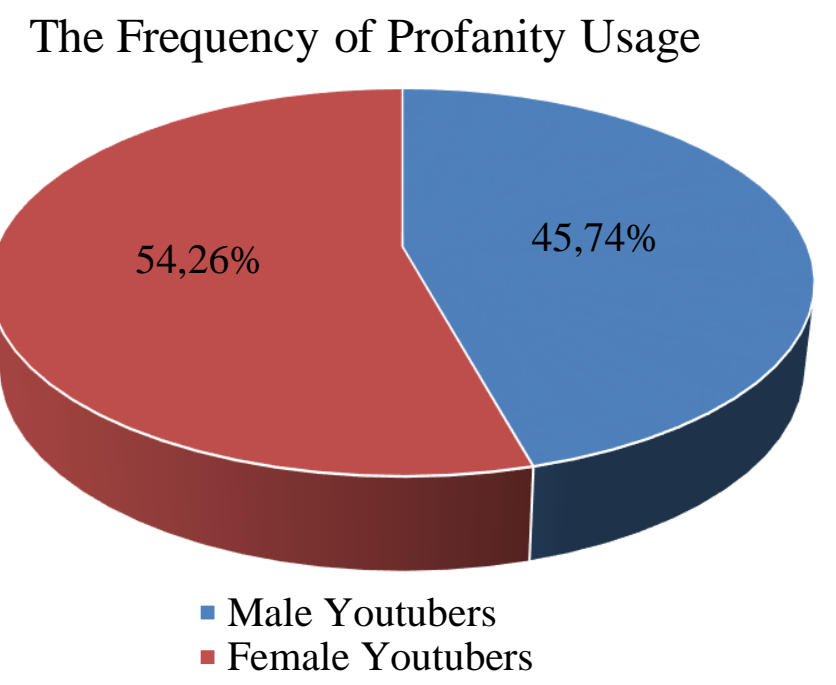

Figure 1

This finding showed that females were more expletive than males. This also meant that female Youtubers were more emotional or expressive in showing their feelings. This was in line with a previous study showed that expletive was not only associated with men but also women (Klerk, 2015). Male Youtubers used more abusive profanity than female did. It can be seen from the data that male used 10 times abusive profanity, while female used it for 3 times.

However, it cannot be stated that male Youtubers were more abusive than female. Because in the videos, some male Youtubers clarified that they used abusive profanity only to prank their viewers. There was no specific offensive or abusive language to cause emotional or psychological injuries to others. Therefore, considering the context where and when the profanity used was crucial to be done.

Both male and female Youtubers used humorous profanity. It can be seen from the data that male used 5 humorous profanity, while female used it for 6 times. The profanity was categorized as humorous since the words or phrases were used to create fun or to make joke 
with others. There was no intention to offend or to cause emotional injuries to others. The examples of this type of profanity were the word "sengak", "sialan", "murahan", "kurang ajar" and etc. Those words and phrases were uttered by male and female Youtubers mostly accompanied by smiling faces. So, smile and laugh were the reactions to those profanity, instead of bad impressions.

The fourth type of profanity was auxiliary profanity. This profanity was the least dominant type used by male and female Youtubers in their videos. Male used is for 1 time and female did too. This type of profanity was defined as an emphasizing swear word. Male and female Youtubers used it to emphasize or strengthen their points in conveying their messages.

Male and female Indonesian Youtubers had their own reasons for using profanity in their videos. As Fieldman et al (2017) said that the reasons for using profanity depended on the person and the situation. Thus, it was important to consider the context of the profanity usage in male and female Youtubers videos. Based on the data analysis in this research, there were five major reasons for using profanity namely to draw attention, to respond pain, to offend, to convey negative thought and to create fun or joke. The first reason was to draw attention. Male Youtubers used profanity for this reason for 12 times, while females used it for 11. It can be inferred that both male and female needed to draw attention so that their videos would be watched by people. The more profanity used, the more popular the videos became. This was in line with the results study which said that there was a relationship between the amount of profanity and Youtube popularity (Moloney \& Sylva, 2020).

The second reason for using profanity was to respond pain or misfortune. There was significant different between male and female Youtubers viewed from this reason. It can be inferred from the result findings that female Youtubers were more expressive than male Youtubers. It can be seen from the data that males used profanity for this reasons 10 times, while females used profanity for this reasons 25 times. This research finding was supported by a previous study which showed that females were more expressive than males (Amir et al., 2012).

The third reason for using profanity was to offend or to cause emotional or psychological injuries. Based on the finding of this research, male Youtubers were more offensive than females. However, from the context in the videos, there was no specific profanity meant to offend someone. It can be seen from the videos that there were some male and female Youtubers clarified that they did not mean to offend others, they just wanted to emphasize their feelings and amuse or entertain the viewers by showing their emotional or expressive feelings. 
This research finding was in line with a previous study which showed that both males and females used profanity to emphasize feelings and express anger (Fine \& Johnson, 1984).

The fourth reason was to convey that the speakers think negatively of a subject matter and to make the listener do the same. For this reason, there was no significant different between male and female Youtubers. It can be seen from the data analysis that male only used profanity for this reason 2 times, while female used it for 1 time.

Basically, both male and female Youtubers realized that their videos contained profanity or swear word and it was bad for people. However, as one of male Youtuber $(D C)$ explained in one of his videos that he used profanity not to abuse people. It was just to emphasize feeling and to convey that something was bad and to make the listeners or the viewers to think the same.

The fifth reason for using profanity was to create fun or to make jokes with others. This reason was used by male Youtubers for 7 times, while female used it for 11 times. It can be inferred that female Youtubers were more active making jokes compared with males. Both male and female Youtubers used profanity with their own various reasons in their Youtube videos. As the technology developed rapidly and the use of language expanded in extreme way, it was quite difficult to decide whether the profanity used by someone was good or bad. Because as this research findings showed that the profanity can be used to draw attention, to make jokes, to convey negative thought, as a response to something and so on. Therefore, in determining the profanity was wrong or right, good or bad, it was important to present the context of who used the profanity, to whom, where and when it was used and also why and how the profanity was used.

The teachers' roles, especially language teachers, as well as parents roles were needed to pay more attention on the profanity language used by people especially Youtubers whose videos were watched by children or young learners. Children as the young learners were vulnerable exposed to the profanity language contained in Youtube videos since there was no supervision of Youtube contents. Therefore, parents and language teachers should know about the profanity. It did not meant that parents and teachers should learn how to use profanity, but they should understand which words categorized as bad language and in what context the profanity were tolerable to be used.

\section{CONCLUSION}


In line with the findings and discussion of this research, the conclusion can stated as: Firstly, there were four types of profanity uttered by male and female Indonesian Youtubers in their videos. The types were expletive, abusive, humorous and auxiliary profanity. Female Youtubers were more expletive than males. Secondly, there were five reasons for male and female Indonesian Youtubers in using profanity. They were to draw attention, to offend, to convey negative thoughts, to respond pain or misfortune and to make fun or jokes. Female Youtubers were more responsive than males.

In line with the conclusions of this research, there were some suggestions can be offered. They were: first, to other researchers and students; it was suggested that this research could be further expanded deeper by exploring different perspective about the use of profanity language in other social media platform such as Messenger App, Facebook or Instagram. Second, to parents and language teachers; it was suggested to understand the types of profanity languages and recognize the media containing profanity so that children and learners could be protected from being exposed to the bad languages. Third, to stakeholders; it was suggested to form a specific institution to supervise the content of Youtube videos so that viewers, especially young ages viewers were safe from being exposed to bad contents. Fifth, to all readers; it was suggested to use this study as an additional reference in using proper language and avoiding the use of swear words in communication.

\section{REFERENCE}

Amir, Z., Abidin, H., Darus, S., \& Ismail, K. (2012). Gender differences in the language use of Malaysian teen Bloggers. GEMA Online Journal of Language Studies, 12(1), 105-124. https://doi.org/10.14020/gema.2012.010218

Byrne, E. (2016). Swearing is Good for You The Amazing Science of Bad Language. In W.W. Norton \& Company.

Creswell, J. W., \& Creswell, J. D. (2018). Research Design Qualitative, Quantitative, and Mixed Methods Approaches. In SAGE Publication (Fifth Edit). Sage Publication.

Feldman, G., Lian, H., Kosinski, M., \& Stillwell, D. (2017). Frankly, We Do Give a Damn: The Relationship Between Profanity and Honesty. Social Psychological and Personality Science, 8(7), 816-826. https://doi.org/10.1177/1948550616681055.

Fine, M. G., \& Johnson, F. L. (1984). Female and Male Motives For Using Obscenity. Journal of Language and Social Psychology, 03(01), 59-74. https://doi.org/10.1177/0261927X8431004.

Joiner, R., Stewart, C., Beaney, C., Moon, A., Maras, P., Guiller, J., Gregory, H., Gavin, J., Cromby, J., \& Brosnan, M. (2014). Publically Different, Privately the Same: Gender 
Differences and Similarities in Response to Facebook Status Updates. Computers in Human Behavior, 39(01), 165-169. https://doi.org/10.1016/j.chb.2014.07.004

Klerk, V. De. (2015). Expletives: Men Only? Communication Monographs, 58(2), 156-169. https://doi.org/10.1080/03637759109376220.

Mercury, R.-E. (1995). Swearing: A "Bad" Part of Language; A Good Part of Language Learning. TESL Canada Journal, 13(1), 28. https://doi.org/10.18806/tesl.v13i1.659.

Miles, M. B., \& Huberman, A. M. (1994). Qualitative Data Analysis An expanded Sourcebook 2nd Edition (Second Edi).

Moloney, M. J., \& Sylva, H. M. (2020). ' And I Swear ...' - Profanity In Pop Music Lyrics On The American Billboard Charts 2009-2018 And The Effect On Youtube Popularity. International Journal of Scientific \& Technology Research, 9(02), 5212-5220. https://doi.org/10.1254/g.hgt.2020.06.721.

Of, A. N. E. (2006). An encyclopedia of swearing: the social history of oaths, profanity, foul language, and ethnic slurs in the English-speaking world. In Choice Reviews Online (Vol. 44, Issue 03). https://doi.org/10.5860/choice.44-1260

Pinker, S. (2008). The Stuff of Thought Language as a Window into Human Nature. In Penguin Books. Penguin Books.

Shit, H. (2014). Holy sh*t: a brief history of swearing. Choice Reviews Online, 51(09), 514862-51-4862. https://doi.org/10.5860/choice.51-4862

Suganob-Nicolau, M. F. (2016). Swear words among young learners: A case study of the elementary students. Indonesian JELT: Indonesian Journal of English Language Teaching, 11(2), 117-132. https://doi.org/10.25170/ijelt.v11i2.1493.

Tanen, D. (1991). You Just Don't Understand. In Ballantine Books. Elsevier BV. https://doi.org/10.1016/0363-8111(91)90045-m

Trudgill, P. (2000). Sociolinguistics: An introduction to language and society. In D. Crystal (Ed.), Penguin Books (Fourth). Penguin Books.

Wahyuningsih, S. (2018). Men and Women Differences in Using Language: A Case Study of Students at STAIN Kudus. Journal of English Education, Literature and Culture, 03(01), 79-90. https://doi.org/10.5636/j.ctf.2018.01.007.

Wulandari, O. (2017). Octavia Wulandari The Use of Swe ar Words in PewDiePie's YouTube Videos. ELITE: English and Literature Journal, 04(02), 1-24. https://doi.org/10.1016/s.scrted.2017.110001. 